\title{
Apical Necrosis and Premature Drop of Persian (English) Walnut Fruit Caused by Xanthomonas arboricola pv. juglandis
}

Concepció Moragrega, Institute of Food and Agricultural Technology-CIDSAV-XaRTA, University of Girona, Campus Montilivi s/n 17071 Girona (Spain); Josep Matias and Neus Aletà, Unitat de Producció Agroforestal, IRTA-Torre Marimon 08140 Caldes de Montbui (Spain); Emilio Montesinos, Institute of Food and Agricultural Technology-CIDSAV-XaRTA, University of Girona, Campus Montilivi s/n 17071 Girona (Spain); and Mercé Rovira, Unitat de Producció Agroforestal, IRTA-Torre Marimon 08140 Caldes de Montbui (Spain)

\begin{abstract}
Moragrega, C., Matias, J., Aletà, N., Montesinos, E., and Rovira, M. 2011. Apical necrosis and premature drop of Persian (English) walnut fruit caused by Xanthomonas arboricola pv. juglandis. Plant Dis. 95:1565-1570.

Etiological and epidemiological aspects of apical necrosis of walnut fruit were studied on cultivars Chandler, Franquette, and Hartley in a Spanish walnut orchard during 2007 and 2008. Affected fruit showed brown necrosis beginning at the blossom end of nuts; these symptoms differed from lesions of common blight of walnut (Xanthomonas arboricola pv. juglandis). X. arboricola pv. juglandis was consistently isolated from apical lesions throughout the growing season. Field isolates reproduced symptoms observed in the orchard when inoculated on immature detached walnut fruit in the laboratory. Sporadic occur-

rence of Fusarium spp. and Alternaria spp., mainly in dropped fruit, was attributed to secondary colonization of apical lesions that were originally caused by $X$. arboricola pv. juglandis. Apical necrosis and common blight were similar in disease epidemiology and cultivar susceptibility; a major increase in epidemics occurred at initial fruit development, and cvs. Chandler and Hartley were more affected than cv. Franquette. Our results suggest that apical necrosis is a new manifestation of walnut blight characterized by distinct symptoms and severe premature fruit drop.
\end{abstract}

Since the late 1990s, a premature walnut fruit drop causing substantial yield loss has been observed in orchards of Persian (English) walnut (Juglans regia L.) in Italy, France, and Spain $(3,5,8,11,13,17)$. In the last 5 years, the same symptoms appeared in the Marmara Region, an important walnut production area in Northwestern Turkey (30). When disease incidence was high, total crop loss occurred in some commercial walnut orchards in Tarragona (Northeastern Spain) (3). The disease was named brown apical necrosis (BAN) according to the symptoms observed in dropped fruit, which consisted of brown to dark brown patches originating exclusively at the blossom end of nuts, and a brown to blackish rot of inner tissues (11). These symptoms are distinct from fruit lesions produced by common bacterial blight (Xanthomonas arboricola pv. juglandis (Pierce) Vauterin et al. [40]), characterized by blackish water-soaked spots, which are not restricted to the blossom end of the fruit (26), and anthracnose (Gnomonia leptostyla (Fr.:Fr.) Ces. \& De Not.), with brown to gray dry spots, often with numerous acervuli (11). At the beginning of fruit development, however, initial apical necrosis in fruit may be confused with lesions of common blight caused by $X$. arboricola pv. juglandis, which consist of small necrotic areas in the bracts and the apical end of nuts. Later, these initial black lesions become depressed, clearly distinct from BAN (26).

BAN of walnut is considered a disease complex whose pathogens include Fusarium spp., Alternaria arborescens, A. tenuissima, and A. alternata $(10,11,19)$. However, the pathogenicity of Alternaria species on walnut has not been proved, and only F. semitectum, F. equiseti, and $F$. graminearum among all Fusarium species isolated from BAN-diseased fruit were pathogenic on walnut (11). Furthermore, preliminary studies in Spanish walnut orchards

Corresponding author: C. Moragrega,

E-mail: concepcio.moragrega @udg.edu

Accepted for publication 11 July 2011.

doi:10.1094/PDIS-03-11-0259

(C) 2011 The American Phytopathological Society showed that $X$. arboricola pv. juglandis was present in apical necrosis lesions, as single infection or in association with Fusarium and Alternaria species (5), suggesting that the bacterium could be involved in the disease. Moreover, crop nutritional problems, soil characteristics, and phenolic contents of walnut fruit could predispose trees to microbial infection and contribute to apical necrosis development $(13,17,32)$. Thus, the etiology of apical necrosis of walnut is at present unclear, and the role of $X$. arboricola pv. juglandis has not been elucidated yet. Additional studies on etiology and epidemiology of this disease are necessary in order to define effective control strategies and reduce crop losses.

The main purpose of our research was to elucidate the role of $X$. arboricola pv. juglandis and other microorganisms in apical necrosis development. Additionally, epidemiological studies on disease progress in the orchard and on disease development in fruit were performed in order to increase knowledge of the disease and discern the relationship between apical necrosis and common blight.

\section{Materials and Methods}

Disease progress in the orchard. Field studies were carried out in 2007 and 2008 in 12-year-old walnut trees of cultivars Franquette, Hartley, and Chandler grafted onto J. regia, in a commercial orchard that was severely affected by the disease, located in Cornudella de Montsant (Tarragona, Northeastern Spain). Trees were arranged on $8 \times 8 \mathrm{~m}$ spacing. Copper sprays or other fungicides were not applied in rows selected for disease studies. In 2008, apical necrosis was not evaluated in cv. Franquette due to low fruit production of this cultivar. Disease incidence was recorded weekly from fruit set (Gf stage [18]) to the end of July, and subsequently at the end of August, in three replicates of three trees per replicate for each walnut cultivar. Dates of fruit set were 14 May 2007 and 22 May 2008 in cvs. Chandler and Hartley, and 25 June 2007 in cv. Franquette. Cultivars were distributed in separate rows in the orchard, and replicates were randomly distributed within cultivar in each row. A total of 100 fruit per tree ( 25 per orientation: N, S, E, and $\mathrm{W}$ ) were analyzed at each date. Additionally, 30 days after fruit set $(\mathrm{Gf}+30)$ and at the end of August, apical necrosis incidence was also monitored in up to 100 dropped fruit per tree, recovered from the ground under the tree canopy. Disease incidence was expressed 
as the percentage of fruit affected by apical necrosis in a tree. Common blight was assessed in the same walnut trees in 2008 ; blight incidence was calculated as the percentage of affected fruit in a total of 100 fruit per tree or in up to 100 fruit dropped to the ground.

Disease development in walnut fruit. Studies were conducted during 2007 and 2008 on the same walnut trees in which the disease was monitored, arranged in three replicates of three trees per replicate. Each week, from the beginning of June to the end of July, and once at the end of August, samples of 10 to 20 fruit with external symptoms of apical necrosis were collected from the walnut trees and from the ground under the tree canopy. Additionally, 50 fruit per cultivar without external disease symptoms were sampled at fruit set for internal symptom evaluation. In the laboratory, symptoms were described and disease development was recorded by indicating the presence of necrosis on each nut tissue (epicarp, mesocarp, endocarp, and seed). Incidence of necrosis on each fruit tissue was determined as percentage of the fruit evaluated per tree. Means of necrosis incidence on each tissue were obtained per replicate, cultivar, and date.

Isolation and identification of microorganisms from lesions. A total of 10 fruit collected from each tree and 5 from the ground were randomly chosen per replicate from those analyzed in the previous assay, and isolation of microorganisms from each necrotic tissue was attempted. Isolations were also performed on the 50 symptomless fruit collected at fruit set. Fruit were surface disinfected by immersion for $1 \mathrm{~min}$ in $1 \%$ sodium hypochlorite solution and rinsed three times in sterile distilled water. Symptomless fruit were cut in half, and each half was placed on either potato dextrose agar (PDA) or Luria Bertani (LB) (23) agar plates for recovering fungi or bacteria, respectively, with the internal side in contact with the medium. For fungal isolation from necrotic tissues, portions of lesions along with healthy tissue were placed on PDA plates and incubated at $22.5^{\circ} \mathrm{C}$ and $16-\mathrm{h}$ photoperiod for 5 days. Colonies were subcultured and pure cultures were identified at genus level on the basis of morphological characteristics (7). Single conidium cultures of Fusarium and Alternaria isolates were preserved on PDA slants at $4^{\circ} \mathrm{C}$ for species identification and pathogenicity tests. Fusarium isolates were identified at species level on the basis of colony morphology on PDA and spore morphology on carnation-leaf agar (CLA) (28). Alternaria isolates were identified at species-group level on the basis of morphological traits $(33,37,38)$.

For bacterial isolation, a 3- to 5-mm piece of the margin of infected tissue was aseptically removed with a scalpel and homogenized in $60 \mu \mathrm{l}$ of sterile distilled water. The resulting suspension was streaked on LB (23), yeast dextrose calcium (YDC), and modified Tween medium (mTM) (36) agar plates and incubated at $27^{\circ} \mathrm{C}$ for 4 days. Additionally, $50 \mu \mathrm{l}$ of the corresponding $1 / 10$ serial dilutions in sterile distilled water were plated on LB and mTM to determine the number of bacteria in a sample. Bacterial

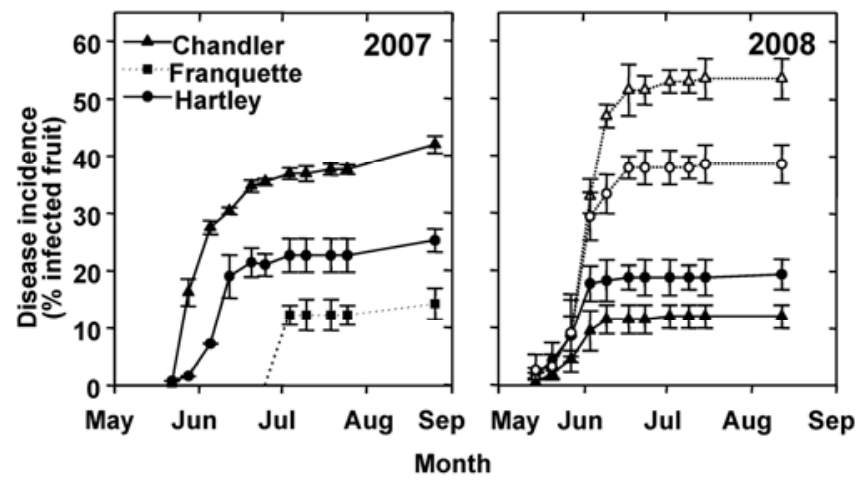

Fig. 1. Disease progress curves of apical necrosis (filled symbols) and common bacterial blight (open symbols) of walnut on fruit of three cultivars in 2007 and 2008. Values are the mean disease incidence in fruit attached to the tree, corresponding to three replicates of three trees per replicate and 100 fruit per tree. Error bars correspond to the mean standard error. colonies displaying morphological characteristics of Xanthomonas spp. on YDC agar and on mTM semiselective medium were selected ( 2 colonies per sample) and purified by restreaking on nutrient agar (NA), and the following biochemical and physiological tests were performed to confirm their identity $(20,36)$ : Gram stain, oxidative and fermentative metabolism of glucose, oxidase reaction, hydrolysis of aesculin and starch, digestion of milk proteins, and growth at $35^{\circ} \mathrm{C}$. Xanthomonadin pigment production was also evaluated by TLC and spectrophotometry (36) for selected representative isolates (one colony per sample). The type strain $X$. arboricola pv. juglandis CFBP 2528 (Collection Française de Bactéries Phytopathogènes, INRA, Angers, France) was used as a reference culture for all determinative tests. Pure cultures of representative isolates of $X$. arboricola pv. juglandis from different walnut fruit tissues and cultivars were stored on YDCA slant tubes at $4^{\circ} \mathrm{C}$ in the dark until use in pathogenicity assays. Cell suspensions of $10^{7}$ to $10^{8} \mathrm{CFU} \mathrm{ml}{ }^{-1}$ in $15 \%$ glycerol were preserved at $-80^{\circ} \mathrm{C}$ for long-term storage.

Pathogenicity assays on detached immature walnut fruit. Twelve isolates of Fusarium ( $F$. semitectum EPS F07, EPS F08, EPS F09, $F$. solani EPS F10, EPS F11, EPS F12, F. chlamydosporum EPS F01, EPS F02, EPS F03, and F. lateritium EPS F04, EPS F05, EPS F06), 9 isolates of Alternaria spp. (EPS A01 to A09), and 21 strains of $X$. arboricola pv. juglandis (EPS 206.6, EPS 206.8, EPS 207.8, EPS 207.14, EPS 207.22, EPS 207.25, EPS 207.31, EPS 207.35, EPS 208.1 to EPS 208.8, EPS 208.10, EPS 208.11, EPS 208.14, EPS 208.26, EPS 208.28, and the type strain CFBP 2528) were evaluated for their pathogenicity on immature Hartley walnut fruit. Symptomless fruit were collected from trees in a commercial walnut orchard in Tarragona (Northeastern Spain) and surface disinfected as described above. Fusarium and Alternaria inocula were obtained from 7-day-old pure cultures on PDA grown at $22.5^{\circ} \mathrm{C}$ and 16 -h light photoperiod. Bacterial suspensions were prepared in sterile distilled water and were obtained from 3day-old cultures grown on NA at $27^{\circ} \mathrm{C}$. Concentration was adjusted to $10^{8} \mathrm{CFU} \mathrm{ml}{ }^{-1}$ according to the optical density $\left(A_{600 \mathrm{~nm}}=0.2\right)$ and confirmed by plating the corresponding $1 / 10$ serial dilutions on NA. Inoculations were performed by placing a 3-mm-long plug of agar with mycelium or $20 \mu \mathrm{l}$ of bacterial suspension on the blossom end of fruit. Inoculated fruit were placed on a grid into plastic boxes filled with wet filter paper and sealed into moistened transparent plastic bags to avoid fruit dehydration and favor microorganism infection. Control fruit were inoculated with sterile distilled water or sterile PDA plugs. Boxes with inoculated fruit were incubated in a controlled environment chamber (SGC 970 Fitotron, Sanyo, Gallenkamp, Leicester, UK) at $25^{\circ} \mathrm{C}$ and 16 -h light photoperiod for 15 days. External and internal symptoms were recorded after the incubation period. Fragments of necrotic tissues were processed as described above, placed on PDA or YDCA plates, and incubated at 25 or $27^{\circ} \mathrm{C}$ for fungi or bacteria reisolation, respectively. Three replicates of 5 fruit per replicate were inoculated with each isolate. The assay was conducted twice.

Statistical analysis. For each walnut cultivar and year, progress curves of disease incidence versus time were plotted, and the area under the disease progress curve (AUDPC) was calculated (15). The effect of cultivar on disease incidence and AUDPC was determined by means of ANOVA using the GLM procedure of SAS system (SAS Institute, Cary, NC, USA). The effect of treatments on disease incidence in the different assays was determined by means of ANOVA using the GLM procedure of SAS. Tukey's means separation test was used to compare treatment means.

\section{Results}

Disease progress in the field. The patterns of disease incidence progress curves were similar in all cultivars in both years (Fig. 1). In cvs. Chandler and Hartley, a rapid increase in disease incidence was observed at early nut development stages, from fruit set to Gf +30 , corresponding to June and early July, after which disease progress slowed. In Franquette fruit, the epidemic began later and was less severe than in the other cultivars (Fig. 1). Disease inci- 
dence on fruit attached to the tree was high in 2007, and significant differences were observed among cultivars in final disease incidence and AUDPC values (Table 1); Chandler and Hartley fruit were consistently more affected by apical necrosis than Franquette fruit. Apical necrosis was also analyzed in dropped fruit (Table 1). A severe premature fruit drop was observed in the 2 years of study, and up to $61 \%$ of Chandler and Hartley dropped fruit were affected by apical necrosis at Gf+30 stage. In 2008, the disease was more severe and most fruit showing apical necrosis dropped to the ground. In fact, up to $71 \%$ of fruit on the ground had dropped before $\mathrm{Gf}+30$ stage, coinciding with the major epidemics increase, and more than $85 \%$ of dropped fruit were found to be affected by the disease at the end of August.

Common blight incidence in fruit was monitored in the same walnut trees in 2008 (Fig. 1). Disease progress curves of apical necrosis and common blight had a similar pattern, but common blight incidence in fruit in the tree was higher because most of the affected fruit remained attached to the tree until harvest. Less than $8 \%$ of fruit on the ground showed lesions of common blight.

Disease development in walnut fruit. External and internal symptoms were similar among the three walnut cultivars. Initial infections consisted of small circular dark brown or blackish lesions restricted to the blossom end, which enlarged to more irregular brown patches. Disease progress on dropped fruit was more extensive than on fruit attached to the tree, and lesions could be externally covered by fungal mycelium. Disease development through inner fruit tissues was analyzed at different fruit ages (Fig. $2)$. A significant effect of tissue and tissue-fruit age interaction $((P$ $>F)<0.01)$ on disease incidence was observed in the 2 years of study, whereas no significant effect of walnut cultivar was observed $((P>F)>0.5)$. Therefore, pooled data of the three cultivars were used in further analysis. Initial infections, from fruit set to Gf +20 , affected epicarp and mesocarp in 85 to $100 \%$ of fruit and progressed to endocarp and seed in 40 to $60 \%$ fruit, depending on year. As fruit grew, internal tissues became more affected, and from Gf +20 to Gf+45, necrosis affected all tissues in 60 to $90 \%$ of fruit. After $\mathrm{Gf}+45$, when fruit shell sclerification was completed, new infections were restricted to external tissues (Fig. 2). From $\mathrm{Gf}+15$ to $\mathrm{Gf}+45$, more than $80 \%$ of dropped fruit showed infection of all internal tissues. Finally, $98 \%$ of externally symptomless fruit recovered from walnut trees at fruit set did not show internal necrosis.

Microorganism isolation. The most prevalent bacteria that were recovered formed yellow colonies, turning yellow-orange with age, were convex and mucoid on YDC, and were surrounded by a small milky inner area and a larger clear outer area on mTM. Biochemical and physiological traits of representative isolates matched those obtained for the $X$. arboricola pv. juglandis type strain CFBP 2528: Gram negative, oxidase negative, oxidative glucose metabolism, growth at $35^{\circ} \mathrm{C}$, ability to hydrolyze aesculin and starch, and protein digestion test positive, thus confirming their identification as $X$. arboricola pv. juglandis. $X$. arboricola pv. juglandis was isolated in 80 to $100 \%$ of fruit in the tree and in 66 to $100 \%$ of dropped fruit (Table 2). Population levels in necrotic tissues ranged from $1 \times 10^{6}$ to $1 \times 10^{8} \mathrm{CFU} \mathrm{g}^{-1}$ fresh tissue.
Fungal colonies obtained from several necrotic fruit samples corresponded to species of Fusarium and Alternaria (Table 2). Occasionally, Cladosporium sp., Stemphylium vesicarium, and Penicillium spp. were recovered. Fungi were isolated at lower frequency than $X$. arboricola pv. juglandis (Table 2). F. chlamydosporum was the most frequent. F. lateritium, F. semitectum, and $F$. solani were also recovered. Most Alternaria isolates belonged to small-spored catenulate species-groups (mainly A. alternata and A. tenuissima).

$X$. arboricola pv. juglandis was isolated (exclusively or with fungi) in high frequency all over the fruit growing period, and was present in all external and internal fruit tissues including the seed (Figs. 3 and 4). No significant effect of fruit age and walnut cultivar on frequency of recovered $X$. arboricola pv. juglandis was observed in the 2 years of study.

The fungal presence in fruit in the tree varied through the fruit growing period (Fig. 3). In 2007, Fusarium and Alternaria were present in up to $60 \%$ of fruit aged from Gf+10 to Gf+45, and increased to up to $75 \%$ at the end of the fruit growing period, while in 2008 fungi were recovered sporadically. Strong differences in fungal frequencies were also observed among walnut fruit tissues (Fig. 4). Fusarium spp. were found in external and internal tissues of Chandler and Hartley fruit, but only in the mesocarp of Franquette fruit. Alternaria spp. were restricted to external tissues of fruit attached to the tree (Fig. 4), but they were present in all tissues, including the seed, in up to $50 \%$ of dropped fruit (Table 2). No microorganisms were recovered in $90 \%$ of asymptomatic walnut fruit collected at fruit set. In a few samples, $X$. arboricola pv. juglandis (7\%) and Fusarium spp. (3\%) were present on healthy nut tissues.

Pathogenicity assays on detached immature walnut fruit. No differences were observed in disease incidence between the two experiments performed $((P>F)=0.1437)$, so data were combined

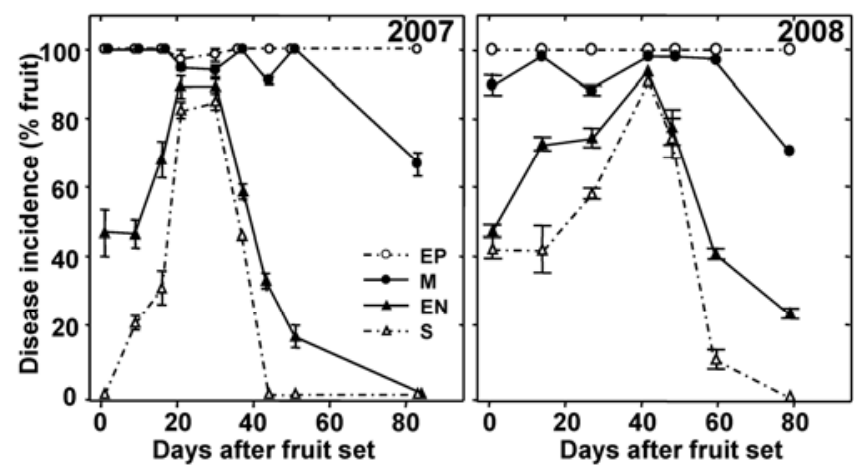

Fig. 2. Incidence of apical necrosis in epicarp (EP), mesocarp (M), endocarp (EN) and seed (S) walnut fruit tissues through the developing period in 2007 and 2008. Pooled data from cultivars Chandler, Hartley, and Franquette are presented. The presence of necrosis on each walnut tissue at each date was recorded on fruit attached to the tree. Values are the means of three replicates of three trees per cultivar and 10 to 20 fruit per tree. Error bars correspond to the mean standard error.

Table 1. Incidence of apical necrosis in fruit of three walnut cultivars in a Spanish walnut orchard during two consecutive growing seasons ${ }^{\mathrm{w}}$

\begin{tabular}{|c|c|c|c|c|c|c|}
\hline \multirow[b]{2}{*}{ Year } & \multirow[b]{2}{*}{ Cultivar } & \multicolumn{2}{|c|}{ Incidence in fruit attached to tree $(\%)$} & \multicolumn{2}{|c|}{ Incidence in dropped fruit $(\%)$} & \multirow[b]{2}{*}{ Total incidence $(\%)^{2}$} \\
\hline & & Final $^{x}$ & AUDPC $^{\mathbf{y}}$ & $\mathbf{G f}+\mathbf{3 0}$ & Final $^{\mathbf{x}}$ & \\
\hline \multirow[t]{3}{*}{2007} & Chandler & $42.7 \mathrm{a}$ & $3,249 \mathrm{a}$ & $25.2 \mathrm{~b}$ & $44.5 \mathrm{a}$ & $43.3 \mathrm{a}$ \\
\hline & Hartley & $25.3 \mathrm{~b}$ & $2,136 \mathrm{~b}$ & $35.3 \mathrm{a}$ & $53.5 \mathrm{a}$ & $39.8 \mathrm{a}$ \\
\hline & Franquette & $14.3 \mathrm{c}$ & $812 \mathrm{c}$ & $19.7 \mathrm{~b}$ & $20.0 \mathrm{~b}$ & $18.1 \mathrm{~b}$ \\
\hline \multirow[t]{2}{*}{2008} & Chandler & $12.3 \mathrm{a}$ & $901 \mathrm{a}$ & $49.4 \mathrm{a}$ & $87.5 \mathrm{a}$ & $49.7 \mathrm{a}$ \\
\hline & Hartley & $19.4 \mathrm{a}$ & $1,375 \mathrm{a}$ & $61.2 \mathrm{a}$ & $85.5 \mathrm{a}$ & $52.2 \mathrm{a}$ \\
\hline
\end{tabular}

${ }^{\text {w}}$ Values are the means of three replicates of three trees and 100 fruit per tree. Means followed by the same letter in a column and year are not significantly different at $P<0.05$ according to Tukey's means separation test.

${ }^{x}$ Final disease incidence was recorded at the end of August.

${ }^{y}$ AUDPC: Area under the disease progress curve was calculated from disease incidence values of fruit that remained attached to the walnut tree.

${ }^{\mathrm{z}}$ Apical necrosis incidence at the end of August of total of fruit analyzed (attached to the tree plus dropped to the ground). 
(Table 2). All except one (EPS 207.14) of the X. arboricola pv. juglandis strains and the type strain CFBP 2528 were pathogenic on walnut fruit. External symptoms of infection were observed 5 days after inoculation, consisting of apical necrotic lesions 2 to 5 $\mathrm{mm}$ in length that grew to 10 to $20 \mathrm{~mm} 10$ days after inoculation. Sixteen strains produced the symptoms of apical necrosis observed in the field, with brown necrotic patches. Three strains (EPS 206.6, EPS 206.8, and EPS 207.31) produced blackish apical infections that were similar to symptoms observed in fruit inoculated with the type strain CFBP 2528 (Table 2). Internal progress of infection was variable, and different levels of aggressiveness were observed among strains. Fifteen of the 19 pathogenic strains, as well as the type strain CFBP 2528, developed internal infections that affected all nut tissues including the seed.

Two isolates of F. semitectum (EPS F07 and EPS F08) and two of $F$. solani (EPS F10 and F12) were pathogenic on walnut fruit (Table 2); inoculated fruit developed external necrosis that progressed internally to the mesocarp, but only occasionally (5\% of fruit) to the seed. Lesions were black and water-soaked and differed from apical necrosis field symptoms. F. chlamydosporum and $F$. lateritium isolates were nonpathogenic on detached immature fruit. The previously inoculated $X$. arboricola pv. juglandis and Fusarium isolates were reisolated from selected infected fruit (one fruit per replicate).

Alternaria isolates were nonpathogenic on walnut fruit (Table 2). However, 20 to 30 days after inoculation, five out of nine isolates produced superficial brown to blackish necrosis surrounding the inoculation point, which in some fruit were covered by fungal mycelium due to Alternaria saprophytic growth on dead tissue.

\section{Discussion}

In the present study, we report that apical necrosis of walnut affects walnut fruit at initial development stages, mainly during the first month of fruit growth. Most affected fruit drop early, and those that initially remain attached to the tree may drop later in the growing season. Although the period of rapid disease increase was similar between apical necrosis and common blight, in the latter case most blight-affected fruit remained attached to the tree until harvest.

In the present report, we provide a detailed description of apical necrosis symptoms and disease progress and demonstrate that apical necrosis of walnut fruit has characteristic symptoms different from common blight infections. Lesions observed in fruit older than Gf +15 were externally and internally distinct from common blight symptoms and matched those described for BAN (11).

Etiological studies performed in our work showed that $X$. arboricola pv. juglandis was consistently present in high frequency in all walnut fruit tissues showing apical necrosis throughout the growing season. Pathogenicity tests demonstrated that $X$. arboricola pv. juglandis strains caused apical infections and reproduced the external and internal symptoms observed in the field. When

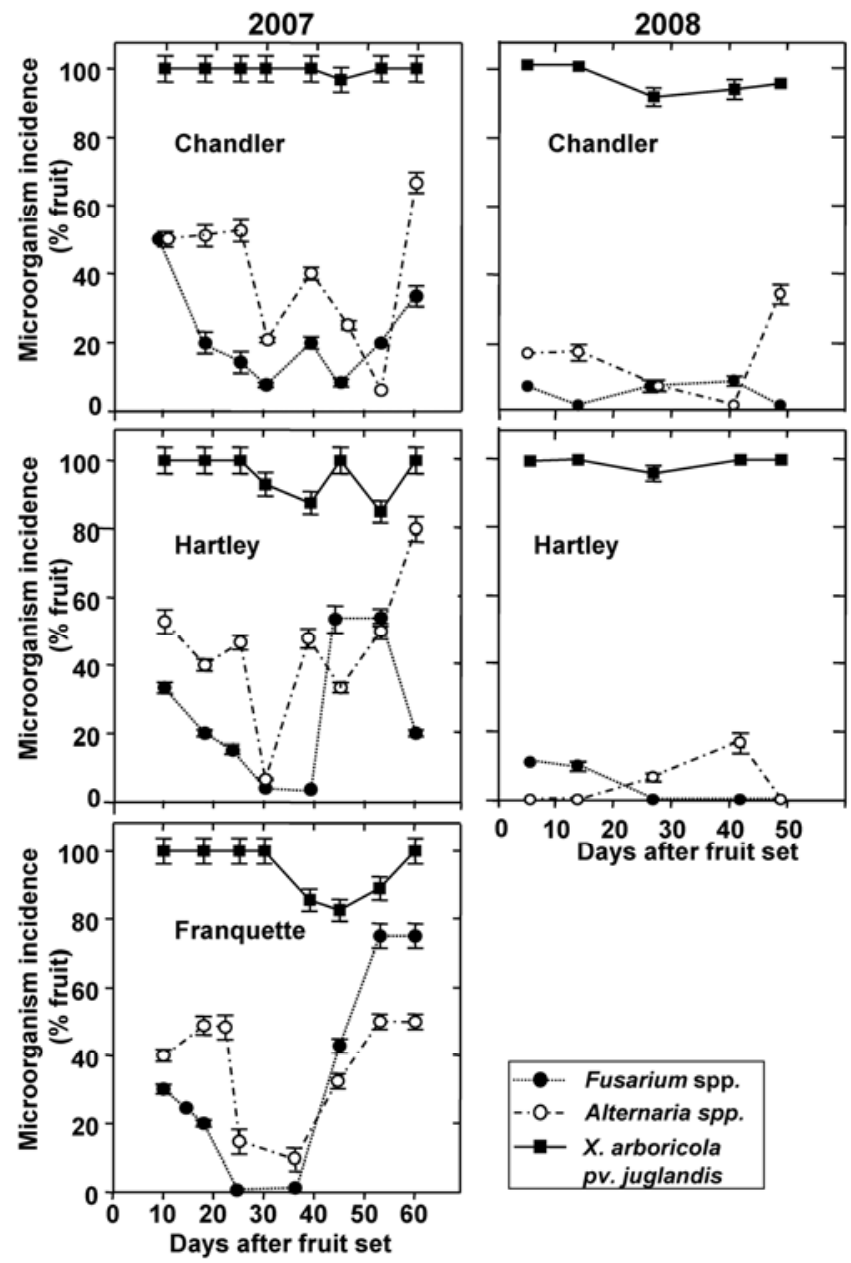

Fig. 3. Incidence of microorganisms in apical necrosis lesions of fruit in the tree of three walnut cultivars in 2007 and 2008 walnut growing sessions. Values are the means of three replicates of three trees and 10 fruit per tree. Error bars correspond to the mean standard error.

Table 2. Frequency of microorganisms recovered from apical necrosis lesions in walnut fruit and pathogenicity on immature fruit tests

\begin{tabular}{|c|c|c|c|c|c|}
\hline \multirow[b]{3}{*}{ Microorganism } & & & \multicolumn{3}{|c|}{ Pathogenicity $^{w}$} \\
\hline & \multicolumn{2}{|c|}{ Frequency $(\% \text { fruit })^{x}$} & \multirow[b]{2}{*}{ Pathogenic $^{y}$} & \multicolumn{2}{|c|}{ Symptoms } \\
\hline & Fruit in tree & Dropped fruit & & Brown apical necrosis & Black apical lesions \\
\hline X. arboricola pv. juglandis & $80-100$ & $66-100$ & + & $80 \%$ & $15 \%$ \\
\hline Fusarium spp. & 35 & 25 & & & \\
\hline F. chlamydosporum & 15 & 10 & - & - & - \\
\hline$F$. lateritium & 6 & 5 & - & - & - \\
\hline F. semitectum & 5 & 6 & + & - & $65 \%$ \\
\hline F. solani & 4 & 4 & + & - & $65 \%$ \\
\hline F. equiseti & oc. $^{\mathrm{z}}$ & oc. & nd & & \\
\hline F. avenaceum & oc. & oc. & nd & & \\
\hline $\begin{array}{l}\text { Alternaria sp. } \\
\text { (small-spored catenulate species) }\end{array}$ & $10-50$ & $20-50$ & - & - & - \\
\hline
\end{tabular}

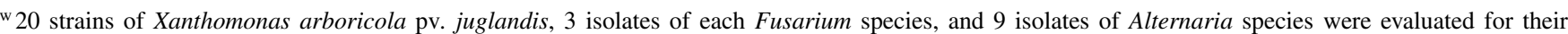
pathogenicity on cv. Hartley immature walnut fruit. Three replicates of 5 fruit per replicate were inoculated with each isolate in two independent experiments.

${ }^{x}$ A total of 1,230 fruit collected from walnut trees and 615 from orchard ground were analyzed. Frequency values vary depending on walnut cultivar, fruit age, and fruit tissue.

y Pathogenicity was determined 15 days after inoculation, as the development of progressive necrosis from the inoculation point. Values correspond to frequency of isolates that were pathogenic. Isolates producing brown or black apical necrosis were differentiated.

${ }^{\mathrm{z}}$ oc: occasionally; nd: not determined. 
these strains were inoculated on leaves of Chandler potted walnut plants, they were also able to develop severe leaf necrosis (C. Moragrega, unpublished data). These results greatly contrast with the fact that until now, apical necrosis of walnut was attributed only to fungal infections (11), probably because the role of $X$. arboricola pv. juglandis in the disease had not been investigated $(5,17)$.

The role of Fusarium spp. in apical necrosis is less certain. F. chlamydosporum, the most frequently isolated Fusarium species from apical lesions, was nonpathogenic on walnut. This species occurs as saprophyte in soil and is frequently present as a saprophyte in seed, cereal grains, and other crops in warmer areas of the world $(24,39)$. In fact, many species of Fusarium are viewed as opportunistic or weak pathogens that are capable of attacking only plants that were weakened previously by some other stress (21). In the present work, only $F$. solani and $F$. semitectum caused external black necrosis in pathogenicity tests, which differed from apical necrosis field symptoms. These two species are regularly recovered from aerial plant organs ( $F$. solani) or root and stem base ( $F$. semitectum) as saprophytes, and they have also been reported to cause diseases in walnut trees as well as other plant species (39). F. solani is the causal organism of stem canker of English walnut in South Africa (16) and in Italy (25), but the disease has not been reported in Spain. F. semitectum has been described as the causal agent of twig cankers on walnut in Argentina (35) and in Italy (9).
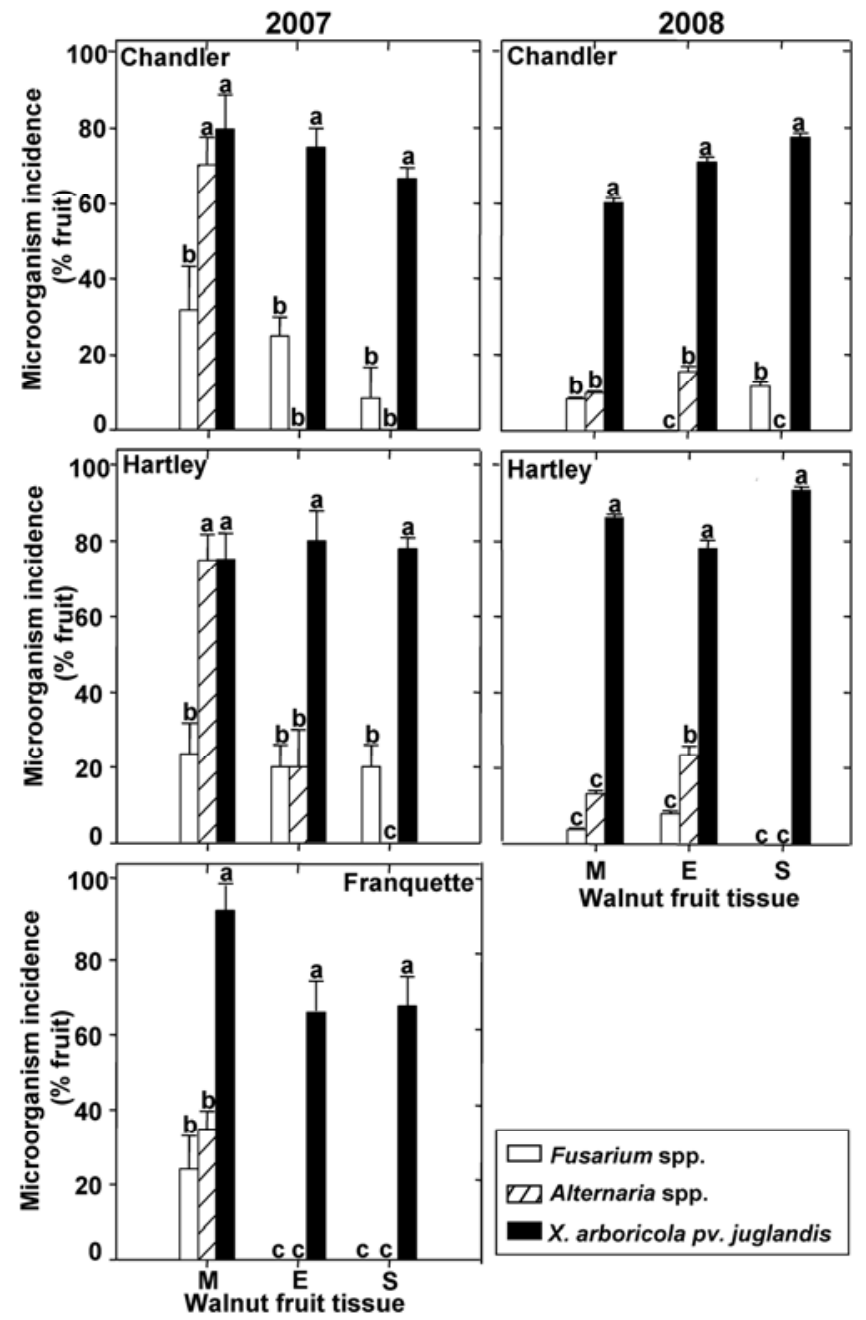

Walnut fruit tissue

Fig. 4. Incidence of microorganisms in mesocarp (M), endocarp (E), and seed (S) tissues of walnut fruit attached to the tree. Values are the mean of five (2008) or seven (2007) sampling dates, each consisting of three replicates of three trees and 10 fruit per tree. Error bars correspond to the mean standard error. Bars with the same letter in a panel are not significantly different at $P<0.05$ according to Tukey's means separation test.
Small-spored catenulate Alternaria taxa are a complex of opportunistic fungi that have been involved in brown apical necrosis of English walnut and gray necrosis of hazelnut $(10,12)$. In our work, Alternaria spp. were occasionally present in fruit that remained on the tree, although they were found more frequently in dropped fruit, especially in old apical infections. Tested Alternaria spp. isolates were nonpathogenic on walnut, but grew as saprophytes on dead fruit tissues later in the incubation period. Therefore, the role of these fungi in apical necrosis appears to be limited to opportunistic colonization of dead fruit tissues.

Thus, on the basis of pathogen prevalence studies and pathogenicity assays, $X$. arboricola pv. juglandis is the primary causal agent of apical necrosis of walnut fruit, whereas Fusarium species could be occasionally involved in the disease interacting with bacterial infections, and Alternaria spp. colonizes dead fruit tissues previously infected by the bacteria. The gradual disease progress typically observed in apical necrosis, from outer to inner walnut fruit tissues, suggests that the inoculum source is external to the kernel tissues. Moreover, externally symptomless fruit did not show internal necrosis.

According to our results, apical necrosis of walnut fruit should be considered a new manifestation of walnut blight rather than a new walnut disease. Despite the fact that apical necrosis is characterized by an intense premature fruit drop and displays specific symptoms, we documented similarities in epidemiological aspects and cultivar susceptibility between apical necrosis and common blight. Disease progress curves showed a similar pattern in all cultivars, and the period of major disease increase was coincident. Most severe common blight infections also occur at the beginning of the walnut growing season $(6,22,27,32)$. Chandler and Hartley were susceptible to apical necrosis, whereas Franquette was less susceptible. Interestingly, Chandler and Hartley have been reported susceptible to common blight. Franquette is considered only slightly susceptible to this disease in Spain $(4,29)$ and California (USA) $(1,2,14)$, but moderately susceptible in French walnut orchards (31).

Further studies, including the characterization of X. arboricola pv. juglandis strains isolated from apical necrosis in comparison with strains isolated from common blight symptoms, could generate further epidemiologically important knowledge on apical necrosis. Genetic diversity among $X$. arboricola pv. juglandis has been reported, and different genomic profiles have been obtained even in strains from the same country (34). Therefore, molecular studies on genetic diversity among $X$. arboricola pv. juglandis populations may help to elucidate the origin of this new manifestation of the common blight disease that affects Mediterranean walnut orchards.

\section{Acknowledgments}

We thank T. Madrid for excellent technical assistance. The research was supported by public funds from the Spanish Government (INIA RTA2005-0010400-00 and CIRIT-Generalitat de Catalunya [2005SGR00835, 2009SGR00812]).

\section{Literature Cited}

1. Adaskaveg, J. E., Förster, H., Thompson, D., Driever, G., Connell, J., Buchner, R., Prichard, T., Grant, J., and Wade, L. 2008. Epidemiology and management of walnut blight. Annual Walnut Research Reports: 181-193. Walnut Marketing Board, Sacramento, CA.

2. Adaskaveg, J. E., Förster, H., Thompson, D., Enns, J., Connell, J., and Buchner, R. 2009. Epidemiology and management of walnut blight. Annual Walnut Research Reports: 241-257. Walnut Marketing Board, Sacramento, CA.

3. Aletà, N., and Ninot, A. 2002. La bactériose et la nécrose apicale du noyer en Espagne. InfoNOIX 19:8.

4. Aletà, N., Ninot, A., Moragrega, C., Llorente, I., and Montesinos, E. 2001 Blight sensitivity of Spanish selections of $J$. regia. Acta Hortic. (ISHS) 544:353-362.

5. Arquero, O., Lovera, M., Rodriguez, R., Salguero, A., and Trapero, A. 2005 Characterization and development of necrotic lesions of walnut tree fruits in southern Spain. Acta Hortic. (ISHS) 705:457-461.

6. Arquero, O., Lovera, M., Rodriguez, R., and Trapero, A. 2005. Walnut blight (Xanthomonas arboricola pv. juglandis): Factors influencing disease incidence. Acta Hortic. (ISHS) 705:443-446.

7. Barnett, H. L., and Hunter, B. B. 1999. Illustrated Genera of Imperfect 
Fungi, 4th ed. American Phytopathological Society, St Paul, MN.

8. Belisario, A., Forti, E., Santori, A., Balmas, V., Valier, A., and Corazza, L. 2001. Fusarium necrosis on Persian (English) walnut fruit. Acta Hortic. 544:389-393.

9. Belisario, A., Luongo, L., Vitale, S., and Santori, A. 2010. First report of Fusarium semitectum as the agent of twig cankers on Persian (English) Walnut in Italy. Plant Dis. 94:791.

10. Belisario, A., Maccaroni, M., Coramusi, A., Corazza, L., Pryor, B. M., and Figuli, P. 2004. First report of Alternaria species-groups involved in disease complexes of hazelnut and walnut fruit. Plant Dis. 88: 426

11. Belisario, A., Maccaroni, M., Corazza, L., Balmas, V., and Valier, A. 2002. Occurrence and etiology of brown apical necrosis on Persian (English) walnut fruit. Plant Dis. 86:599-602.

12. Belisario, A., and Santori, A. 2009. Gray necrosis of hazelnut fruit: A fungal disease causing fruit drop. Acta Hortic. (ISHS) 845:501-506.

13. Bouvet, G. 2005. Walnut blight-apical necrosis: Test of agronomic control. Acta Hortic. (ISHS) 705:447-449.

14. Buchner, R. P., Olson, W. H., McGranahan, G., Teviotdale, B., Leslie, C., and Gilles, C. K. 2003. Evaluation of blight response in walnut selections, introductions and cultivars. Annual Walnut Research Reports: 401-403. Walnut Marketing Board, Sacramento, CA.

15. Campbell, C. L., and Madden, L. V. 1990. Introduction to Plant Disease Epidemiology. John Wiley \& Sons, New York.

16. Chen, W., and Swart, W. J. 2000 First report of stem canker of English walnut caused by Fusarium solani in South Africa. Plant Dis. 84:592.

17. Garcin, A., and Duchesne, D. 2001. Walnut blight and apical necrosis. Acta Hortic. (ISHS) 544:379-387.

18. Germain, E., Jalinat, J., and Marchou, M. 1973. Biologie florale du Noyer (Juglans regia L.). Bull. Tech. Inf. 282.

19. Hong, S. G., Maccaroni, M., Figuli, P. J., Pryor, B. M., and Belisario, A. 2006. Polyphasic classification of Alternaria isolated from hazelnut and walnut fruit in Europe. Mycol. Res. 110:1290-1300.

20. Lelliott, R. A., and Stead, D. E. 1987. Methods for the Diagnosis of Bacterial Diseases of Plants. Blackwell Scientific Publications, Oxford.

21. Leslie, J. F., Pearson, C. A. S., Nelson, P. E., and Toussoun, T. A. 1990. Fusarium spp. from corn, sorghum, and soybean fields in the Central and Eastern United States. Phytopathology 80:343-350.

22. Lindow, S. E., Buchner, R. P., Olson, W. H., and Koutsoukis, R. 2004. Epidemiological approaches to the control of walnut blight disease. Annual Walnut Research Reports: 291-314. Walnut Marketing Board, Sacramento, CA.

23. Maniatis, T., Fritsch, E. F., and Sambrook, J. 1982. Molecular Cloning: A Laboratory Manual. Cold Spring Harbor Laboratory, Cold Spring Harbor, NY.

24. Marasas, W. F. O., Kriek, N. P. J., Wiggins, V. M., Steyn, P. S., Towers, D. K., and Hastie, T. J. 1979. Incidence, geographical distribution, and toxigenicity of Fusarium species in South African corn. Phytopathology 69:1181-1185.
25. Mazzaglia, A., Fabi, A., Belisario, A., Librandi, I., Cefalo, G., Varvaro, L. and Anselmi, N. 2005. Bark cankers on English walnut: An emerging disease. Acta Hortic. (ISHS) 705:437-442.

26. Miller, P. W., and Bollen, W. B. 1946. Walnut bacteriosis and its control. Oregon Agric. Exp. Stn. Tech. Bull. 9.

27. Mulrean, E. N., and Schroth, M. N. 1982. Ecology of Xanthomonas campestris pv. juglandis on Persian (English) walnuts. Phytopathology 72:434-438.

28. Nelson, P. E., Tousson, T. A., and Marasas, W. F. O. 1983. Fusarium Species: An Illustrated Manual for Identification. Pennsylvania State University, University Park, PA.

29. Ninot, A., Aletà, N., Moragrega, C., and Montesinos, E. 2002. Evaluation of a reduced copper spraying program to control bacterial blight of walnut. Plant Dis. 86:583-587.

30. Özaktan, H., Akat, S., Akköprü, A., and Yavas, M. 2009. Etiological approach to brown apical necrosis on walnut fruits in Turkey. Files of the COST 873 WG1-4 Meeting: Active research to combat bacterial diseases of stone fruits and nuts resistance and control strategies against bacterial diseases of stone fruits and nuts. Cetara (Italy). http://www.cost873.ch/ uploads/_files/Hozaktan_BANTurkey_Italy_1.pdf.

31. Radix, P., Bastien, C., Jay-Allemand, C., Charlot, G., and Seigle-Murandi, F. 1998. The influence of soil nature on polyphenols in walnut tissues. A possible explanation of differences in the expression of walnut blight. Agronomie 18: 627-637.

32. Radix, P., Seigle-Murandi, F., and Charlot, G. 1994. Walnut blight: Development of fruit infection in two orchards. Crop Prot. 13:629-631.

33. Roberts, R. G., Reymond, S. T., and Anderson, B. 2000. RAPD fragment pattern analysis and morphological segregation of small-spored Alternaria species and species group. Mycol. Res. 104:151-160.

34. Scortichini, M., Marchesi, U., and Di Prospero, P. 2001. Genetic diversity of Xanthomonas arboricola pv. juglandis (synonyms: X. campestris pv. juglandis; $X$. juglandis pv. juglandis) strains from different geographical areas shown by repetitive polymerase chain reaction genomic fingerprinting. J. Phytopathol. 149: 325-332.

35. Seta, S., González, M., Lori, G. 2004. First report of walnut canker caused by Fusarium incarnatum in Argentina. Plant Pathol. 53:248.

36. Shaad, N. W., Jones, J. B., and Chum, W. 2001. Laboratory Guide for Identification of Plant Pathogenic Bacteria, 3rd ed. American Phytopathological Society, St. Paul, MN.

37. Simmons, E. G. 1992. Alternaria taxonomy: Current status, view-point, challenge. Pages 1-35 in: Alternaria: Biology, Plant Disease and Metabolites. J. Chelkowski and A Visconti, eds. Elsevier, Amsterdam.

38. Simmons, E. G. 1995. Alternaria themes and variations (112-144). Mycotaxon 55:55-163.

39. Summerell, B. A., Salleh, B., and Leslie, J. F. 2003. A utilitarian approach to Fusarium identification. Plant Dis. 87:117-128.

40. Vauterin, L., Hoste, B., Kerster, K., and Swings, J. 1995. Reclassification of Xanthomonas. Int. J. Syst. Bacteriol. 45:472-489. 